\title{
Erratum
}

\section{A Parasitological Survey of European Sea Bass (Dicentrarchus Labrax) and Gilthead Sea Bream (Sparus Aurata) Cultured in Italy}

M.L. Fioravanti*, M. Caffara, D. Florio, A. Gustinelli and F. Marcer

Department of Veterinary Public Health and Animal Pathology, Faculty of Veterinary

Medicine, University of Bologna, Ozzano Emilia (BO), Italy

*Correspondence: Dipartimento di Sanità Pubblica Veterinaria e Patologia Animale Facoltà di Medicina Veterinaria, via Tolara di Sopra, 50 - 40064, Ozzano Emilia (BO), Italy E-mail: fioravanti@vet.unibo.it

Veterinary Research Communications, 30 (Suppl.1) 2006, 249-252

Tables I and II in this article were badly laid out, for which the publishers apologise. The correct layout of the Tables is given below:

TABLE I

Parasites found in European sea bass (Dicentrarchus labrax)

\begin{tabular}{|c|c|c|c|c|c|c|}
\hline \multirow{3}{*}{$\begin{array}{l}\text { Parasites from } \\
\text { European sea bass }\end{array}$} & \multicolumn{6}{|c|}{ No. of positive subjects - percentage of positivity } \\
\hline & \multirow[b]{2}{*}{ Extensive } & \multicolumn{4}{|c|}{ Intensive } & \multirow[b]{2}{*}{ Total } \\
\hline & & I & IFC & OFC & SC & \\
\hline \multicolumn{7}{|l|}{ Sarcomastigophora } \\
\hline Amyloodinium ocellatum & $99-34.1 \%$ & $52-12.6 \%$ & - & - & - & $151-11.6 \%$ \\
\hline Cryptobia branchialis & $45-15.5 \%$ & $2-0.5 \%$ & - & - & $1-0.5 \%$ & $48-3.7 \%$ \\
\hline \multicolumn{7}{|l|}{ Ciliophora } \\
\hline Trichodina spp. & $63-21.7 \%$ & $55-13.3 \%$ & & - & - & $118-9.1 \%$ \\
\hline Sessiline Peritrichs & $3-1 \%$ & - & - & - & - & $3-0.2 \%$ \\
\hline \multicolumn{7}{|l|}{ Apicomplexa } \\
\hline Eimeria bouixi & $1-0.3 \%$ & $8-1.9 \%$ & $8-2.2 \%$ & $6-15 \%$ & $3-1.6 \%$ & $26-2 \%$ \\
\hline Microspora & - & $28-6.8 \%$ & - & - & - & $28-2.2 \%$ \\
\hline \multicolumn{7}{|l|}{ Myxozoa } \\
\hline Sphaerospora dicentrarchi & $139-47.9 \%$ & $243-59 \%$ & $142-38.7 \%$ & $13-32.5 \%$ & $5-2.6 \%$ & $542-41.6 \%$ \\
\hline S. testicularis & - & - & $17-4.6 \%$ & - & - & $17-1.3 \%$ \\
\hline Ceratomyxa labracis & $2-0.7 \%$ & $34-8.3 \%$ & $7-1.9 \%$ & $6-15 \%$ & $18-9.3 \%$ & $67-5.1 \%$ \\
\hline C. diplodae & - & $7-1.7 \%$ & $30-8.2 \%$ & - & - & $37-2.8 \%$ \\
\hline Enteromyxum leei & - & $15-3.6 \%$ & - & - & - & $15-1.2 \%$ \\
\hline \multicolumn{7}{|l|}{ Platyhelminthes Monogenea } \\
\hline Diplectanum aequans & $138-47.6 \%$ & $221-53.6 \%$ & $142-38.7 \%$ & $1-2.5 \%$ & $13-6.7 \%$ & $515-39.6 \%$ \\
\hline \multicolumn{7}{|l|}{ Arthropoda Crustacea } \\
\hline Caligus minimus & - & $4-1 \%$ & - & - & - & $4-0.3 \%$ \\
\hline
\end{tabular}

The online version of the original article can be found at http://dx.doi.org/10.1007/s11259-006-0053-5 
TABLE II

Parasites found in gilthead sea bream (Sparus aurata)

\begin{tabular}{|c|c|c|c|c|c|c|}
\hline \multirow{3}{*}{$\begin{array}{l}\text { Parasites from } \\
\text { gilthead sea bream }\end{array}$} & \multicolumn{6}{|c|}{ No. positive subjects - percentage of positivity } \\
\hline & \multirow[b]{2}{*}{ Extensive } & \multicolumn{4}{|c|}{ Intensive } & \multirow[b]{2}{*}{ Total } \\
\hline & & I & IFC & $\mathrm{OFC}$ & $\mathrm{SC}$ & \\
\hline \multicolumn{7}{|l|}{ Sarcomastigophora } \\
\hline Amyloodinium ocellatum & - & $10-5.8 \%$ & - & - & - & $10-2.2 \%$ \\
\hline Scuticociliatida & - & $5-2.9 \%$ & $3-2.8 \%$ & - & - & $8-1.7 \%$ \\
\hline \multicolumn{7}{|l|}{ Ciliophora } \\
\hline Cryptocaryon irritans & - & $22-12.7 \%$ & - & - & - & $22-4.8 \%$ \\
\hline Trichodina spp. & $10-30.3 \%$ & - & $2-1.9 \%$ & - & - & $12-2.6 \%$ \\
\hline Sessiline Peritrichs & $16-48.5 \%$ & - & $11-10.4 \%$ & - & - & $27-5.9 \%$ \\
\hline Microspora & - & - & $15-14.2 \%$ & - & - & $15-3.3 \%$ \\
\hline \multicolumn{7}{|l|}{ Myxozoa } \\
\hline Ceratomyxa sparusaurati & - & $3-1.7 \%$ & $2-1.9 \%$ & - & - & $5-1.1 \%$ \\
\hline Polysporoplasma sparis & - & $5-2.9 \%$ & $48-45.3 \%$ & - & - & $53-11.6 \%$ \\
\hline Enteromyxum leei & - & $20-11.6 \%$ & - & $43-71.7 \%$ & - & $63-13.8 \%$ \\
\hline Leptotheca sparidarum & - & $32-18.5 \%$ & - & - & - & $32-7 \%$ \\
\hline \multicolumn{7}{|l|}{ Platyhelminthes Monogenea } \\
\hline Sparicotyle chrysophrii & - & - & $13-12.3 \%$ & - & $15-17.4 \%$ & $28-6.1 \%$ \\
\hline Furnestinia echeneis & - & $5-2.9 \%$ & $7-6.6 \%$ & - & - & $12-2.6 \%$ \\
\hline \multicolumn{7}{|l|}{ Platyhelminthes Digenea } \\
\hline Sanguinicolidae (eggs) & - & - & $12-11.3 \%$ & - & - & $12-2.6 \%$ \\
\hline \multicolumn{7}{|l|}{ Arthropoda Crustacea } \\
\hline Caligus spp. & $3-9.1 \%$ & - & - & - & - & $3-0.7 \%$ \\
\hline Ergasilus spp. & - & - & $12-11.3 \%$ & - & - & $12-2.6 \%$ \\
\hline
\end{tabular}

